\title{
METHODS OF CHECKING PRINTED CIRCUITS ${ }^{\dagger}$
}

\author{
I. HAJDU, P. BÁNLAKI, J. PINKOLA and E. TÓTH \\ Technical University, Budapest, Hungary
}

(Received November 1, 1982; in final form August 1, 1983)

Printed circuits make up to 20 to 40 per cent of the value of electronic circuits.

Quality and reliability requirements have been boosted by the general use of complex integrated circuits. An economical and high quality production is preconditioned by the continuous checking of prime materials and technologies.

After a brief review of checking methods, a short examination of quality testing of the end product (double or multilayer printed circuit board) is given, involving checking methods of assembled and non assembled boards.

Modern electronic components exhibit failure rates of $10^{-7}$ to $10^{-9}$ per hour. A corresponding reliability is expected from printed circuit boards. According to our tests, this level of reliability is achieved if the production process meets five requirements such as:

1. Raw materials strictly meeting the test requirements specified in IEC 326 recommendations. ${ }^{1}$

2. Adequate dimensional stability and density of circuit artwork films.

3. Checking and maintaining at an optimum value technology parameters throughout in the production line.

4. Efficient checking at least two points during the manufacturing process.

5. Final check and sorting of finished boards.

Quality testing of raw materials and films, as well as effects of design and technology on the quality and reliability have been discussed in our previous papers..$^{2,3}$ Some problems of testing during manufacture and after finishing will be dealt with in the present paper.

Production testing may be organized according to either of the following two strategies:

- In order to meet average requirements, the testing procedure is followed - if needed and if possible - by repair. Thereby production economy may be improved by 20 to 30 per cent.

- Under raised reliability requirements, manufacture checks reject faulty boards. Faults repaired during manufacture may produce hidden sources of error.

The final check methods and acceptance requirements to be selected are much dependent on the expected environmental effects and the expected economy (output).

Environmental effects are often extreme (such as in certain industrial plants and in space travel research). In such cases, boards approved in final checks have to be further

\footnotetext{
${ }^{\dagger}$ Paper originally presented at the 5th International Spring Seminar on Electrotechnology held at Prenet, Czechoslovakia, 1-4 June, 1982.
} 
screened. An efficient screening involves the following exposures:

- Temperature

- Temperature shock

- Humidity

- Vibration

Deep seated screening tests may involve revision of the strategy of production checking. Namely hidden faults arising from repair are normally detected by screening exposures. This is the only method to follow in the production of high-reliability multilayer boards of high unit value.

Manufacturers often do not know exactly users' requirements. In such cases, checking of printed circuit boards as a purchased product by the user is essential. A universal observation is that users generally do not check boards before assembling. Checking costs of assembled and unassembled boards differ by an order of magnitude as a rule. In selecting the checking system for a given production process, this general statement has, of course, to be refined.

- Costs differ less for systems containing none or a few circuit elements of high functional density.

- A distinction has to be made between available checking methods and the costs of mass-production and small-batch or individually made systems.

In plants equipped with automatic measuring instruments checking mass produced low functional density integrated circuit boards before assembly may not be found to be economical. One hundred per cent checking of purchased products is economical for systems containing LSI and VLSI and also for several hundred circuits containing simpler active means. In some user plants it is inadvisable to do such checks. In these cases a manufacturer offering printed circuit boards with a certificate of reliability has to be selected.

Elements of, and relationships between manufacture and final testing, as well as foreign product checking at the users plant are seen in Figure 1.

The proportion of different types of faults found in assemblies made with printed circuits is presented in Figure 2.

At Budapest Technical University, printed circuit technologies for making highreliability boards at a competitive cost level have been developed. Our prototype

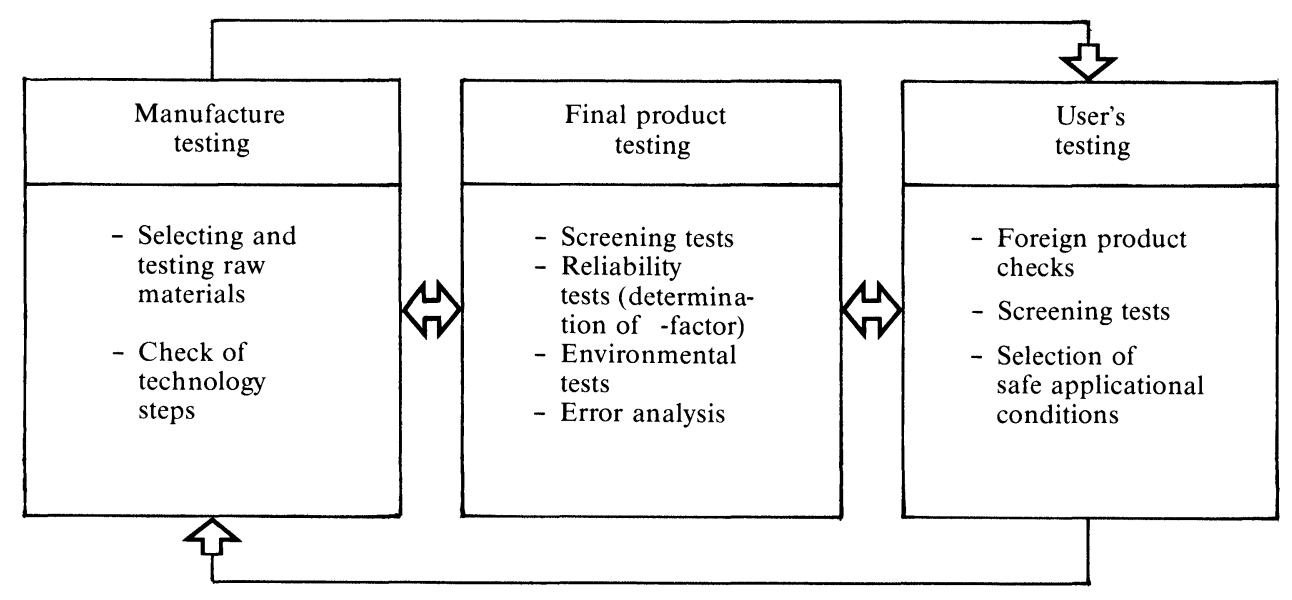

FIGURE 1. Test methods of PCBs 


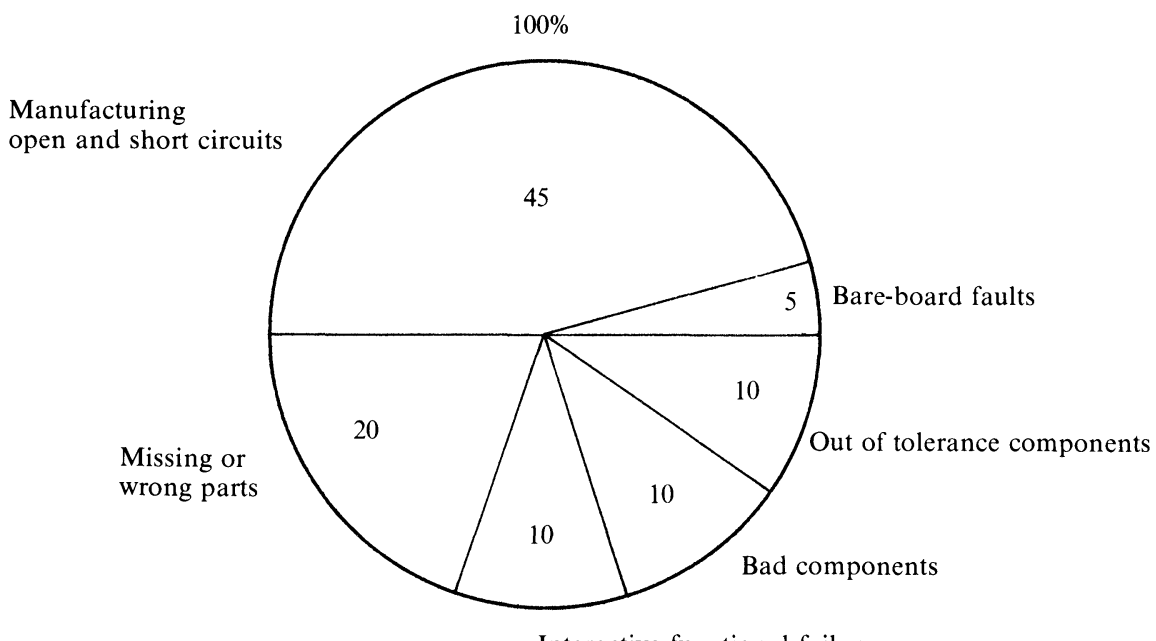

FIGURE 2 Fault types of PCBs

products have been successfully applied in the electronics requirements of several industrial plants, in certain computers of the "Unified Computer System" and in some instruments of the "Intercosmos" programme.

\section{REFERENCES}

1. IEC 326 Standard Recommendation.

2. E. Tóth, "Technology impacts on printed circuit board reliability", Acta Polytechnica - CVUT 17, III.3. p. $105,(1978)$.

3. I. Hajdu, "Examination of printed circuit boards". Third International Spring Seminar on Electronics Technology, p. 138-144, May 15-18. (1979), Balatonfüred, Hungary.

4. I. Hajdu, J. Pinkola, E. Tóth, "Erfahrungen bei Prüfungen an gedruckten Schaltungen”, 26. Internationales Wissenschaftliches Kolloqüium, Heft 3. TH Ilmenau, DDR, p. 163-167, (1981). 

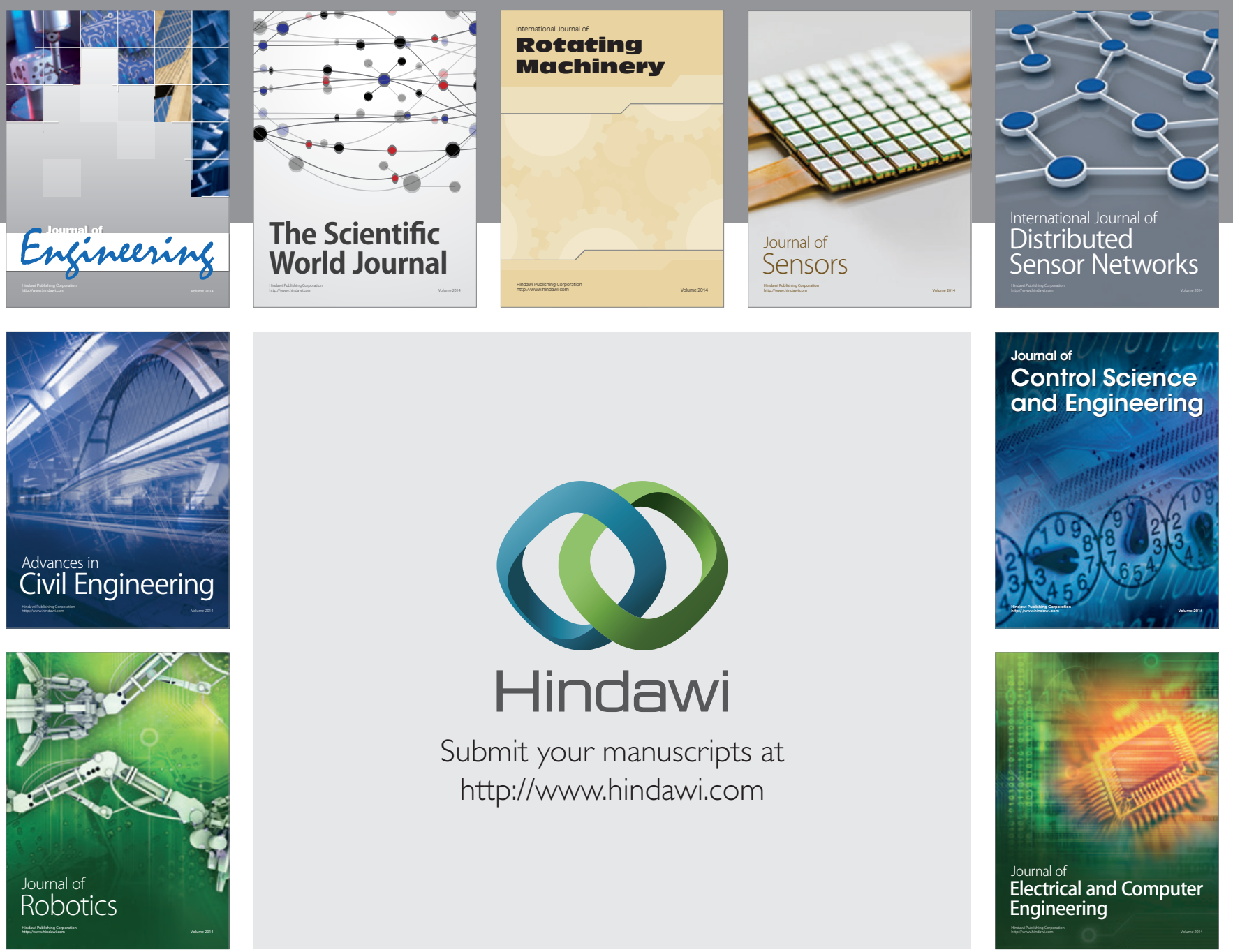

Submit your manuscripts at

http://www.hindawi.com
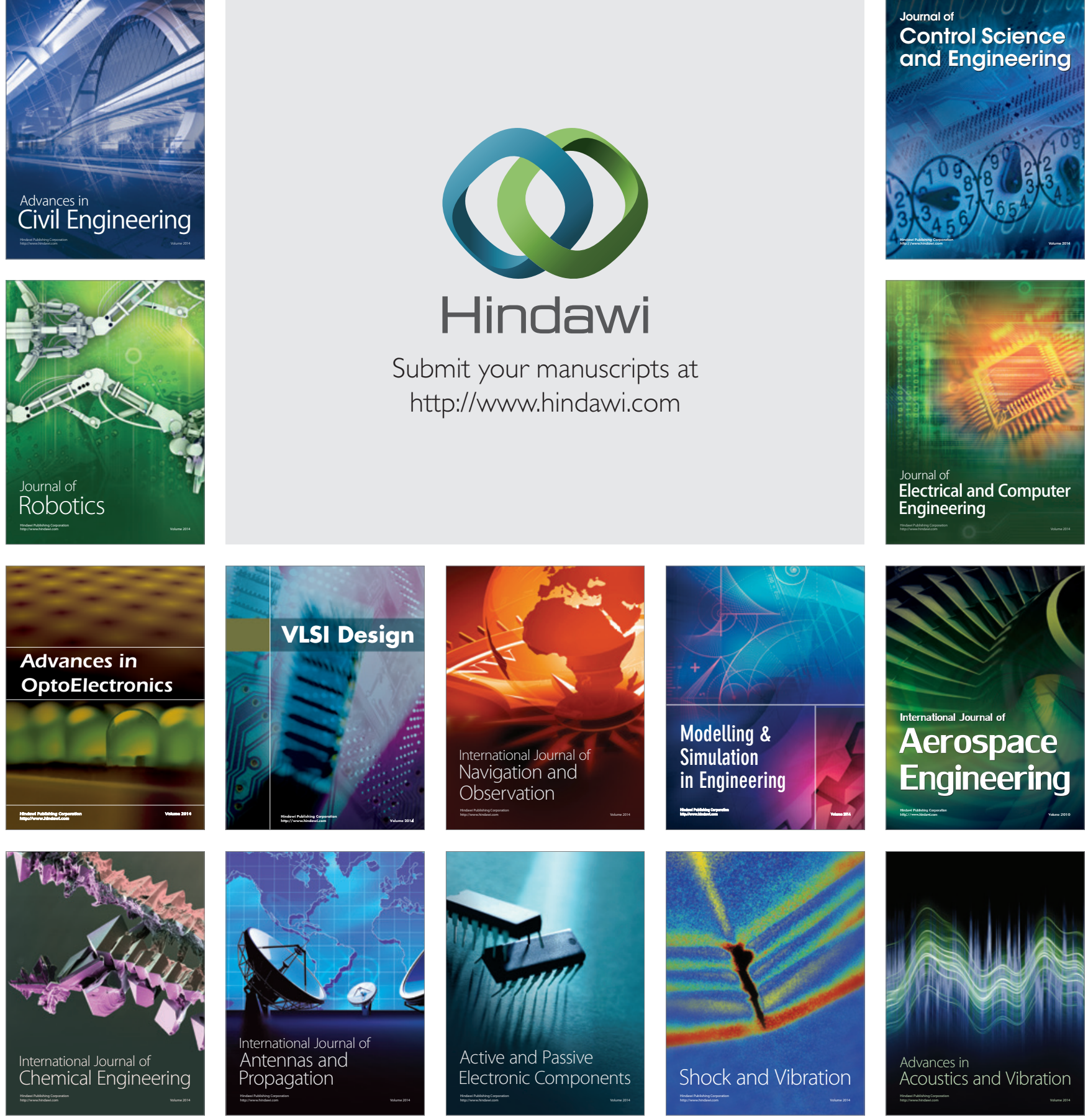